\section{Strategies for Direct Sequencing of PCR-amplified DNA}

\author{
Venigalla B. Rao
}

Department of Biology, Institute for Biomolecular Studies, The Catholic University of America, Washington, D.C. 20064
The amplification of target DNA by $\mathrm{PCR}^{(1)}$ followed by direct sequencing of amplified $\mathrm{DNA}^{(2)}$ has emerged as a powerful strategy for rapid molecular genetic analysis. Using this strategy, the time-consuming cloning steps can be bypassed completely, and the sequence of the target DNA can be determined directly from a crude biological sample. The crude sample can be cultured cells, bacteria, or a viral preparation. Furthermore, the copy number of target DNA in the sample can be as low as one to a few molecules of genomic DNA among a vast excess of contaminating nontarget DNA. ${ }^{(3,4)}$ This review describes two sequencing strategies. These would allow generation of DNA sequence from almost any PCR-amplified DNA template. In addition, factors that influence the sequencing reactions that would allow manipulation of these strategies for specific sequencing needs are discussed. For a more comprehensive analysis of the direct sequencing strategy, the reader is referred to reviews by Gyllesten ${ }^{(2)}$ and Rao. ${ }^{(5)}$

\section{SEQUENASE STRATEGY}

This strategy consists of three steps. ${ }^{(6)}$ In the first step, the double-stranded PCR-amplified DNA is denatured to single strands, and the sequencing primer is annealed to the complementary sequence on one of the template strands. In the second step, the annealed primer is extended by DNA polymerase by 20-80 nucleotides, incorporating multiple radioactive labels into the newly synthesized DNA. This step is performed under nonoptimal reaction conditions so that the enzyme would act in a low-processive fashion, synthesizing only short stretches of DNA. In the third step, the labeled DNA chains are extended and terminated by incorporation of ddNMP.

\section{Reaction components}

DNA template The PCR-amplified DNA should be first separated from the unused dNTPs and primers by Qiagen spin-20 or Qiaquick ion-exchange column chromatography (Qiagen Inc). The concentration of recovered DNA template can be estimated by agarose gel electrophoresis and ethidium bromide staining of a small aliquot of the purified DNA, and by comparing the intensity of the stained band with that of a standard DNA of known concentration. Alternatively, the DNA concentration can be estimated by using a DNA dipstick (InVitrogen). A DNA concentration in the range of $\sim 1$ pmole is desirable to generate high-intensity sequence ladders. However, concentrations as low as 0.1 pmole can be used.

Sequencing primer A 20-nucleotide DNA primer synthesized by an oligonucleotide synthesizer can be used directly as a sequencing primer without any purification steps involving HPLC or polyacrylamide gel electrophoresis. Concentration of the primer is estimated by absorbance at $260 \mathrm{~nm}$.

DNA polymerase Sequenase, version 2.0 (U.S. Biochemical), is the most suitable enzyme for performing this protocol. Sequenase is a modified phage T7 DNA polymerase that has no $3^{\prime} \rightarrow 5^{\prime}$ exonuclease activity. Sequenase is active at low temperatures and incorporates multiple radioactive labels efficiently to generate high-intensity sequence ladders.

Sequencing buffer The composition of the sequencing buffer varies with the polymerase used. For Sequenase, the buffer is $40 \mathrm{~mm}$ Tris- $\mathrm{HCl}(\mathrm{pH} 7.5), 20$ $\mathrm{mM} \mathrm{MgCl}_{2}$, and $50 \mathrm{~mm} \mathrm{NaCl}$.

Radiolabeled dNTP Approximately $5 \mu \mathrm{Ci}$ of either $\left[\alpha{ }^{32} \mathrm{P}\right] \mathrm{dATP},\left[\alpha^{35} \mathrm{~S}\right] \mathrm{dATP}$, or $\left[\alpha^{33} \mathrm{P}\right] \mathrm{dATP}$ is used for each set of sequencing reactions. $\left[\alpha-{ }^{32} \mathrm{P}\right] \mathrm{dATP}$ is, however, the preferred radionucleotide.

\section{Sequencing Protocol}

The following is a Sequenase protocol (U.S. Biochemical) modified for sequencing PCR-amplified DNA. 
1. Set up extension-termination reaction mixtures. Transfer $2.5 \mu l$ of each of the four dNTP/ddNTP mixtures to four independent tubes. Each tube will receive $80 \mu \mathrm{M}$ of each of four dNTPs and $8 \mu \mathrm{M}$ of ddATP, ddTTP, ddGTP, or ddCTP. Preincubate these tubes at $37^{\circ} \mathrm{C}$ for $5 \mathrm{~min}$ before initiating the extension and chain-termination reactions (see below).

For sequencing GC-rich templates, dGTP should be replaced with 7-deazadGTP (U.S. Biochemical) to overcome compression artifacts that are known to occur during sequencing gel electrophoresis. ${ }^{(7)}$ It could also be replaced with dITP, but dITP may not be a good substrate for all DNA polymerases.

2. Mix $\sim 1$ pmole of PCR-amplified DNA, 10 pmoles of sequencing primer, $2 \mu \mathrm{l}$ of $5 \times$ sequencing buffer, and $\mathrm{H}_{2} \mathrm{O}$ in a total reaction volume of $10 \mu \mathrm{l}$. Addition of nonionic detergents such as Tween 20 and NP-40 to a final concentration of $0.5 \%$ was reported to improve the specificity of annealing of the sequencing primer to the template. ${ }^{(8)}$ Incubate the samples in a heat block at $95^{\circ} \mathrm{C}$ for $8 \mathrm{~min}$. Chill the tubes on ice for $1 \mathrm{~min} .{ }^{(9)}$ Spin in a microcentrifuge at $10,000 \mathrm{rpm}$ for $10 \mathrm{sec}$. Transfer the tubes to ice, and immediately proceed to the next step. Note: The above annealing conditions are applicable only to the double stranded PCR-amplified DNA templates. For single-stranded templates, such as the products of asymmetric PCR, ${ }^{(10)}$ the gradual cooling technique is preferred. In this procedure, the above mixture should be incubated in a $65^{\circ} \mathrm{C}$ heat block for $6 \mathrm{~min}$ and gradually cooled to $30^{\circ} \mathrm{C}$ by turning off the heat block.

3. To the above mixture on ice, add $2 \mu$ of cold dNTP mix containing 0.75 $\mu \mathrm{M}$ each of dTTP, dGTP, and dCTP, and $5 \mu \mathrm{Ci}$ of $\left[\alpha{ }^{32} \mathrm{P}\right] \mathrm{dATP}$ (sp. act. 3000 $\mathrm{Ci} / \mathrm{mmole}$, Amersham), $1 \mu \mathrm{l}$ of $0.1 \mathrm{M}$ dithiothreitol, $\mathrm{H}_{2} \mathrm{O}$, and 2 units of freshly diluted Sequenase, version 2.0, to a final reaction volume of $15.5 \mu \mathrm{l}$. Incubate the reaction mixture on ice for 2 min to label DNA.

4. Transfer $3.5 \mu \mathrm{l}$ of the above mixture to each of the four dNTP/ddNTP tubes that are preincubated at $37^{\circ} \mathrm{C}$ as described above (step 1). Allow the extension and chain-termination reactions to proceed for $5 \mathrm{~min}$ at $37^{\circ} \mathrm{C}$.

5. Stop the extension and chain-termination reactions by adding $4 \mu \mathrm{l}$ of Stop buffer containing $95 \%$ formamide, $20 \mathrm{~mm}$ EDTA, $0.05 \%$ bromophenol blue, and $0.05 \%$ xylene cyanol FF. If the samples are not used immediately, they can be stored at $-70^{\circ} \mathrm{C}$ for $\sim 1$ week. However, it is preferable to use the samples within 2 days. Heat the samples in a $80^{\circ} \mathrm{C}$ heat block for $3 \mathrm{~min}$, and load a 2- to 3- $\mu$ l aliquot of the sample in each lane of a sequencing gel.

\section{Important Characteristics of this Protocol}

1. The labeling step is the most critical step in this protocol and should be performed under well-controlled conditions. In this step, the annealed primer is extended by only $20-80$ nucleotides to incorporate multiple radioactive labels into the newly synthesized DNA. Because the Sequenase enzyme is highly processive and synthesizes several thousand nucleotides $(\sim 4000$ nucleotides with Sequenase version 2.0) at a stretch before dissociating from the complex, this step should be performed under low processivity conditions such as low temperature, and low concentrations of dNTPs. ${ }^{(6)}$

2. A common pitfall of this procedure is the appearance of either very faint sequence ladders or no sequence ladders on the final autoradiograph. However, an intense band is seen in the high-molecular-weight position. This characteristic pattern is attributable to a lack of control at the labeling step. If the labeling reactions are not controlled well, the Sequenase enzyme, instead of synthesizing a short stretch of DNA, predominantly synthesizes the fulllength product. Consequently, the sequence ladders representing the shorter chain-terminated products constitute a minor fraction and therefore appear as faint bands. This can be controlled by modifying the labeling conditions in 


\section{IIIIIManual Supplement}

such a way that the enzyme will act in a low processive manner. These modifications include decreasing the enzyme concentration, decreasing the unlabeled dNTP concentration, reducing reaction time, and increasing the template concentration.

3. This protocol requires the incorporation of at least one radioactive label into the newly synthesized DNA in order to visualize a band on the autoradiograph. Therefore, the sequence of the first nucleotide that could be determined by this protocol will depend on the distance between the $3^{\prime}$ end of the primer and the first labeled [ $\left.{ }^{32} \mathrm{P}\right] \mathrm{dAMP}$ incorporated. If the template is known to be, or suspected to be, a GC-rich template, use of $\left[\alpha-{ }^{32} \mathrm{P}\right] \mathrm{dCTP}$ rather than $\left[\alpha-{ }^{32} \mathrm{P}\right] \mathrm{dATP}$, is recommended.

\section{CYCLE SEQUENCING PROTOCOL}

Based on the report by Murray, ${ }^{(11)}$ a number of PCR-directed sequencing strategies, ${ }^{(12-14)}$ referred to as cycle sequencing strategies, have been developed for direct sequencing of PCR-amplified DNA. These strategies take advantage of the powerful automated cycling capability of thermal cyclers to amplify chain-terminated sequencing products for generating high-intensity sequence ladders. Each sequencing cycle consists of three steps. First, the PCR-amplified DNA is denatured to single strands. This is followed by annealing of a ${ }^{32} \mathrm{P}$-labeled sequencing primer to the complementary sequence on one of the strands. In the final step, the annealed primer is extended and chain-terminated by a thermostable DNA polymerase. The resulting partially double-stranded chain-terminated product is then denatured in the next sequencing cycle, releasing the template strand for another round of priming reactions while accumulating chain-terminated products in each cycle. These steps are repeated $20-40$ cycles to amplify the chain-terminated products in a linear fashion.

\section{Reaction Components}

DNA template As in the Sequenase protocol, the PCR-amplified DNA should be first purified by Qiagen spin-20 or Qiaquick column chromatography (Qiagen Inc.) to remove unused dNTPs and primers. It is possible, however, to use 1-2 $\mu$ l of the unpurified PCR product directly for cycle sequencing. However, the overall quality of the sequence ladders generated will not be as good as with the purified DNA. Therefore, purification of amplified DNA is recommended. When sequencing a large number of templates routinely, the purification step can be bypassed by using the recently described modified cycle sequencing strategies. ${ }^{(13,14)}$ In these strategies, lower concentrations of dNTPs $(10-20 \mu \mathrm{M}$ of each dNTP) and primers (10 pmoles of each primer) are used for amplification of the target DNA. As a result, the carryover of unused dNTPs and primers into the sequencing reactions is minimized. It is desirable to have a template DNA concentration of at least 0.1 pmole for each set of sequencing reactions to generate high-intensity sequencing ladders. Lower template concentrations can be used, but the sequence ladders generated will be of low intensity.

Sequencing primer The sequencing primer is labeled with ${ }^{32} \mathrm{P}$ at the $5^{\prime}$ end using $\left[\gamma^{32} \mathrm{P}\right] A T P$ and $\mathrm{T} 4$ polynucleotide kinase. The ratio of primer, kinase, and $\left[\gamma^{32} \mathrm{P}\right] \mathrm{ATP}$ should be maintained at an optimal level to achieve high specific activity labeling of the sequencing primer (see below). High specific activity of the primer, but not the total activity, is critical for generating high-intensity sequence ladders. Alternately, it is possible to use $\left[\alpha{ }^{32} \mathrm{P}\right] \mathrm{dATP}$ or $\left[\alpha-{ }^{33} \mathrm{P}\right] \mathrm{dATP}$ and label newly synthesized DNA, rather than using a $5^{\prime}$ labeled primer (Promega). However, this will generate higher background (see below). In addition, there will be a greater degree of nonuniformity in 
the intensity of the bands generated. For example, chain-terminated products of high molecular weight incorporate radioactive labels at severalfold higher frequency when compared with those of low molecular weight.

DNA polymerase Any thermostable DNA polymerase that lacks $3^{\prime} \rightarrow 5^{\prime}$ exonuclease can be used. Taq polymerase (Perkin-Elmer), which has no $3^{\prime} \rightarrow 5^{\prime}$ exonuclease activity, is the most widely used enzyme. ${ }^{(15)}$ Other enzymes that are used for cycle sequencing include Pfu polymerase (exonuclease-minus) (Stratagene), Vent polymerase (exonuclease-minus) (New England Biolabs), and $T u b$ polymerase (Amersham).

\section{Sequencing Protocol}

The following is a basic protocol for Taq polymerase. The same can be used as well for other thermostable polymerases. But the buffer conditions and dNTP/ddNTP ratios should be modified accordingly for each polymerase used. Many factors would affect the optimal dNTP/ddNTP ratios required for generating high-intensity sequence ladders with low background (see below). Therefore, it is highly recommended that the dNTP/ddNTP ratios be optimized for a given sequencing application.

1. Labeling the primer: Mix $10-15$ pmoles of sequencing primer, $50 \mu \mathrm{Ci}$ $\left[\gamma^{-32}\right.$ P]ATP [sp. act. $6000 \mathrm{Ci} / \mathrm{mmole}$ or $>6000 \mathrm{Ci} / \mathrm{mmole}(\mathrm{NEG}-035 \mathrm{C}, \mathrm{NEN})$ ], $5 \mu \mathrm{l}$ of $10 \times$ kinase buffer $\left(70 \mathrm{~mm}\right.$ Tris- $\mathrm{HCl}$ at $\mathrm{pH} 7.5,10 \mathrm{~mm} \mathrm{MgCl}_{2}$, and $5 \mathrm{~mm}$ dithiothreitol, or the one supplied by the vendor), and $\mathrm{H}_{2} \mathrm{O}$, to a final reaction volume of $50 \mu \mathrm{l}$. Preincubate the reaction mixture at $37^{\circ} \mathrm{C}$ for $5 \mathrm{~min}$. Add $1 \mu \mathrm{l}$ of freshly diluted T4 polynucleotide kinase (10 units), and incubate at $37^{\circ} \mathrm{C}$ for $30 \mathrm{~min}$. Add an additional $1 \mu \mathrm{l}$ aliquot of freshly diluted kinase (10 units), and continue incubation at $37^{\circ} \mathrm{C}$ for $30 \mathrm{~min}$. Removal of unincorporated $\left[\gamma_{-}{ }^{32} \mathrm{P}\right] \mathrm{ATP}$, although not critical, is recommended. This can be accomplished by gel filtration through a Biospin-10 column (Bio-Rad). The labeled primer can be stored at $-70^{\circ} \mathrm{C}$ for at least 2 weeks.

2 . Transfer $2 \mu \mathrm{l}$ of each of the four dNTP/ddNTP extension-termination mixtures to four tubes. Each tube will receive $30 \mu \mathrm{M}$ of each of four dNTPs and $1.2 \mathrm{mM}$ of ddATP or $1.2 \mathrm{~mm}$ of ddTTP, $90 \mu \mathrm{M}$ of ddGTP, or $600 \mu \mathrm{M}$ of ddCTP. As in the Sequenase protocol, dGTP should be replaced with deaza-dGTP (U.S. Biochemical) for GC-rich templates to overcome compression artifacts that occur during sequencing gel electrophoresis. ${ }^{(7)}$

3. Mix 0.1-0.2 pmole of Qiagen-purified PCR-amplified DNA, 1-2 pmoles of $5^{\prime}-{ }^{32} \mathrm{P}$-labeled sequencing primer, $2 \mu \mathrm{l}$ of $10 \times$ Sequencing buffer, and 5 units of Taq polymerase, in a total reaction volume of $20 \mu$ l. Reagents such as dimethylsulfoxide (DMSO), Triton X-100, Tween 20, or NP-40, may be added to this mixture to enhance the quality of sequence ladders. ${ }^{(8)}$

4. Transfer $4 \mu \mathrm{l}$ of the above mixture to each of the four tubes containing dNTP/ddNTP mixtures (from step 2). Mix the contents and overlay with $20 \mu \mathrm{l}$ of mineral oil.

5. Place the tubes in a thermal cycler that has been preheated to $94^{\circ} \mathrm{C}$ and initiate thermal cycling. Each cycle will consist of denaturation at $94^{\circ} \mathrm{C}$ for 1 min, annealing at $40-60^{\circ} \mathrm{C}$ for $30 \mathrm{sec}$, and extension and chain termination at $72^{\circ} \mathrm{C}$ for $30 \mathrm{sec}$. These steps are repeated for $20-40$ cycles.

6. After completion of thermal cycling, add $4 \mu \mathrm{l}$ of Stop buffer containing $95 \%$ formamide, $20 \mathrm{~mm}$ EDTA, $0.05 \%$ bromophenol blue, and $0.5 \%$ xylene cyanol FF to the reaction mixture. Mix and centrifuge for a few seconds in a microcentrifuge to separate the layers. If the samples are not used immediately, they can be stored at $-70^{\circ} \mathrm{C}$ for $\sim 1$ week; however, it is preferable to use the samples within 2 days. Heat the samples in a $80^{\circ} \mathrm{C}$ heat block for 3 min, and load a 2- to $3-\mu l$ aliquot of the aqueous phase in a single well of the sequencing gel. 
Manipulation of the Size Range of Sequence Ladders

Most of the compositions of dNTP/ddNTP mixtures reported in the literature, or available commercially, are optimized to generate sequence ladders of high intensity and uniformity in the range of 50-200 nucleotides from the 3' end of the primer. Generally, the sequence ladders closer to the primer (1-50 nucleotides from the $3^{\prime}$ end of primer) are of low intensity under these conditions. If high-intensity sequence ladders are desired very close to the primer (in the 1- to 100-nucleotides range), $\mathrm{Mn}^{2+}$ can be added to the sequencing reactions. ${ }^{(16)}$ DNA polymerases incorporate ddNTPs $\sim 5$ - to 10 -fold more frequently in the presence of $\mathrm{Mn}^{2+}$. Because $\mathrm{Mn}^{2+}$ effects are seen in the presence of $\mathrm{Mg}^{2+}$, no changes to the basic protocols are required other than the addition of $\mathrm{Mn}^{2+}$. Different polymerases require different $\mathrm{Mn}^{2+}$ concentrations for optimal results. ${ }^{(13,16)} \mathrm{A} \mathrm{Mn}^{2+}$ concentration of $3.5 \mathrm{~mm}$ is optimal for Sequenase for increasing the frequency of terminations by about fivefold. $\left(\mathrm{Mn}^{2+}\right.$, prepared as a stock solution of $100 \mathrm{mM} \mathrm{MnCl}_{2}$ in $150 \mathrm{mM}$ sodium isocitrate, is available from U.S. Biochemical). If sequence ladders far from the primer (in the 200- to 400-nucleotide range) are to be generated, the dNTP/ ddNTP ratios should be increased by simply adding an appropriate aliquot (this would vary depending on the polymerase used) of a dNTPs stock solution to the extension-termination mixture. This will decrease the frequency of terminations, and, therefore, increase the average length of the chainterminated products.

\section{FACTORS THAT INFLUENCE SEQUENCINC REACTIONS}

\section{Carryover Nucleotides and Primers}

In a standard PCR, $\sim 200 \mu \mathrm{M}$ each of four dNTPs and 50 pmoles each of two primers are used to amplify several micrograms of target DNA. Of these, $>97 \%$ of dNTPs and $>90 \%$ of primers remain unused at the end of PCR. ${ }^{(5,13)}$ Unless these are removed, direct use of PCR-amplified DNA as a sequencing template would result in the carryover of unused dNTPs and primers to the sequencing reactions. These will interfere with the sequencing reactions in the following ways: (1) The carryover dNTPs alter the dNTP/ddNTP ratios that are required for optimal chain-termination reactions; (2) because the carryover primers can also prime DNA synthesis, they compete with the sequencing primer and titrate out polymerase as well as dNTPs and ddNTPs; and (3) as a result of priming by carryover primers, a mixture of sequence ladders would be generated by the Sequenase protocol because the DNA synthesized from the PCR primers will also be radioactively labeled.

As a consequence of the above interferences, the sequence ladders generated will be of low intensity with high background. Thus, it would be difficult to decipher DNA sequence from such ladders. It is therefore essential to remove the unused dNTPs and primers from PCR mixtures. A number of strategies have been reported for separation of low-molecular-weight dNTPs and primers from the high-molecular-weight PCR-amplified DNA. ${ }^{(5)}$ These include differential precipitation, ion-exchange chromatography, gel filtration, and streptavidin chromatography. Of these, ion-exchange chromatography may be the best way to quantitatively remove the low-molecularweight dNTPs and primers from PCR-amplified DNA. In our experience, Qiagen spin-20 or Qiaquick spin column separation gave clean DNA templates and generated high-intensity sequence ladders. These columns are designed to resolve either the single-stranded or the double-stranded PCR-amplified DNA from dNTPs and PCR-primers that are $<50$ nucleotides long.

Heterogeneity of DNA template

The PCR-amplified DNA is a product of virtually billions of in vitro priming 
and extension reactions. Therefore, inherent in the PCR process is the amplification of heterogenous DNA in addition to the unique target DNA. These heterogenous DNA molecules differ in sequence and size and arise as a result of secondary reactions. ${ }^{(5)}$ These include (1) partial products generated by premature termination of DNA synthesis, (2) mosaic products generated by random intermolecular recombination between target DNA strands, and (3) multiple products generated as a result of priming at sequences that have either accidental homology or functional relatedness to the target DNA of interest.

Most of the standard PCRs predominantly amplify the unique target DNA while the heterogenous DNA constitute a minor fraction. This fraction usually appears as a smear upon agarose gel electrophoresis and ethidium bromide staining. However, it is not uncommon to see that a major portion of the amplified DNA is constituted by heterogenous DNA. This happens particularly when the copy number of starting sample is low or when PCRs are performed under low-stringency conditions. ${ }^{(4,17)}$ Depending on the extent present in the PCR-amplified DNA, the heterogenous DNA will accordingly contribute to background in the final sequence ladders.

Two major factors that lead to the formation of heterogenous DNA are strand annealing and random priming during PCR amplification (see below). Therefore, careful consideration should be given in designing the parameters for PCR amplification. In particular, primer design, annealing temperature, and conditions or treatments prior to the initiation of first PCR cycle should be stringently controlled to amplify only the target DNA. In general, a highquality PCR-amplified product is generated by choosing highly specific PCR primers with a GC content of $>50 \%$, using a high annealing temperature that is very close to the estimated $T_{\mathrm{m}}$ value of the primers (in the range of 50$60^{\circ} \mathrm{C}$ ), initiating PCR by hot start, and if necessary, performing a second nested PCR with an internal set of primers. ${ }^{(17)}$ In addition, PCR should be performed for as few cycles as possible using a high copy number of target DNA. In spite of these modifications, if considerable background still exists, or when multiple products are amplified, it is essential to purify the desired amplified product by agarose gel electrophoresis. The DNA fragment is extracted from the agarose gel by any standard procedure, ${ }^{(5)}$ and used as a template for sequencing reactions.

\section{Random Priming}

Random priming, as opposed to specific priming by the sequencing primer, refers to priming of DNA synthesis at random points on any DNA strand in the reaction mixture. Random priming is facilitated by the interaction of a few nucleotides at the $3^{\prime}$ end of the sequencing primer with a short stretch of complementary sequence at a random position on DNA. ${ }^{(5)}$ Such complexes, although inherently unstable, are rapidly stabilized by addition of few nucleotides by the highly active DNA polymerase (in vitro synthetic rate of Taq polymerase is on the order of 5000 nucleotides per min). Random priming events are also facilitated by the ends of PCR-amplified DNA. Because it is a linear molecule, PCR-amplified DNA consists of numerous $3^{\prime}$ ends, each having a free hydroxyl group. These $3^{\prime}$ ends, especially the ends of short partial products formed during PCR, are capable of priming DNA synthesis in a random fashion. As a result, a mixture of random chain-terminated products will be generated in addition to the specific chain-terminated products. The random products will appear as background bands in all lanes when $\left[\alpha^{32} \mathrm{P}\right] \mathrm{dATP}$ is used for labeling DNA, either by the Sequenase strategy or by the cycle sequencing strategy.

The random priming events can be minimized by the following consider- 
ations. First, use of a $5^{\prime}$-labeled primer rather than $\left[\alpha-{ }^{32} \mathrm{P}\right] \mathrm{dATP}$ in the cycle sequencing protocol would eliminate this background. This is because the random chain-terminated products will not be radioactively labeled and, therefore, will not appear on the final autoradiograph. However, even under these conditions, extensive random priming should be avoided, as the random events, by competing with the specific events for polymerase and dNTPs, would reduce the intensity of the specific bands.

Random priming can also be minimized by choosing a stringent annealing temperature. In general, very low temperature of annealing (snap cooling, ${ }^{(9)}$ as in Sequenase protocol), or a high temperature of annealing (close to the estimated $T_{\mathrm{m}}$ value of primers as in cycle sequencing protocol), improves the specificity of priming. However, a high annealing temperature $\left(50-60^{\circ} \mathrm{C}\right)$, as in the cycle sequencing protocol, should be preferred over the snap cooling procedure because a temperature shift from $94^{\circ} \mathrm{C}$ (denaturation temperature) to $50-60^{\circ} \mathrm{C}$ (annealing temperature) can be accomplished by a thermal cycler in $<30 \mathrm{sec}$. This would minimize random priming events as well as the strand annealing events (see below).

\section{Strand Annealing}

The PCR-amplified DNA is a linear double-stranded molecule of several hundred nucleotides. But, the DNA polymerases used for in vitro DNA synthesis cannot replicate a double-stranded template because they lack the accessory proteins such as single-stranded DNA-binding protein, helicase, etc. Therefore, the double-stranded PCR product will have to be first converted to single-stranded form. This is accomplished by heating PCR-amplified DNA at $94^{\circ} \mathrm{C}$ for several minutes. But the denatured single strands tend to reassociate, reconstituting the double-stranded form. This will have two consequences. First, if this happens during the annealing step, binding of the primer to the template and priming of DNA synthesis would be inefficient, leading to the appearance of very low intensity sequence ladders. The two protocols described above are therefore designed to minimize the time required for the annealing step. This would favor the kinetics of annealing of a short primer to the template rather than that of the opposite strand, which is several hundred nucleotides long. Presence of detergents such as NP-40 and Tween 20, and possibly also DMSO, may further inhibit strand annealing and improve the quality of sequence ladders generated. ${ }^{(8)}$ A second problem associated with strand annealing involves the extension step. Even when annealing of primer to template occurred, extension by polymerase can be hindered because of strand annealing in the regions downstream from the replication fork. Consequently, DNA synthesis is terminated randomly, resulting in the dissociation of polymerase from the replication complex. These random stops, resulting from ddNTP-independent terminations, would appear as background bands in all four lanes. This is one of the primary reasons for the appearance of high background in the sequence ladders generated from the PCR-amplified DNA. In addition to the random stops, stops could also occur at a high frequency at specific points on the template. For instance, GC-rich regions of the template tend to form double-stranded complexes readily and generate a specific terminated product at a much higher frequency than a random product. These "strong-stop" products would appear as intense bands in all four lanes at specific positions on the autoradiograph.

The strand-annealing problems can be overcome by the following modifications: (1) Sequencing reactions should be performed under high-stringency conditions, for example, use of high annealing and extension temperatures for short time periods; clearly, the cycle sequencing protocol is best suited for maintaining high-stringency conditions during sequencing reac- 
tions; (2) concentrations of ddNTPs required for chain-termination should be optimized to generate predominantly ddNTP-specific terminations that would far outweigh the nonspecific terminations; and (3) because the products of ddNTP-independent terminations will have a free 3 '-hydroxyl group, these can be extended further by terminal dideoxynucleotidyl transferase in a template-independent manner; this enzyme will convert the background bands to high-molecular-weight products that will be retained at the top of the sequencing gel, thereby reducing the background. ${ }^{(18)}$ Finally, strand-annealing problems can be eliminated by generating a single-stranded DNA template either by asymmetric $\mathrm{PCR}^{(10)}$ or by converting the double-stranded PCR-amplified DNA into single-stranded half-templates using phage T7 gene 6 exonuclease $^{(19)}$ (U.S. Biochemical).

\section{CONCLUSIONS}

Direct sequencing of PCR-amplified DNA bypasses the time-consuming cloning steps and rapidly generates accurate DNA sequence information from small quantities of precious biological samples. Although this approach generates considerable background, in most cases, it does not preclude the researcher from generating complete and accurate DNA sequence information. As discussed above, this background can be minimized by performing both the PCR and DNA sequencing reactions under stringent conditions. The two strategies described above would allow determination of DNA sequence from almost any type of PCR-amplified DNA template. Although both protocols are expected to generate high-intensity sequence ladders, the cycle sequencing strategy is preferred over the Sequenase strategy because it is very convenient to set up, especially when it is necessary to generate DNA sequence routinely from a large number of templates. Also, reaction parameters, such as random priming and strand annealing, can be controlled stringently using the cycle sequencing strategy. This is particularly useful for generating sequence from templates having a high GC content because the extension and chain-termination reactions can be performed at an elevated temperature, which destabilizes secondary structures in the DNA template. In summary, high-intensity, low-background sequence ladders can be consistently generated directly from PCR-amplified DNA by (1) performing PCR under stringent conditions, (2) purifying the PCR-amplified DNA from unused dNTPs and primers by Quiagen chromatography, (3) performing cycle sequencing under stringent conditions, and (4) using a high-specific-activity 5'-labeled sequencing primer for amplifying chain-terminated products.

\section{REFERENCES}

1. Mullis, K., F. Faloona, S. Scharf, R. Salid, G. Horn, and H. Erlich. 1986. Specific enzymatic amplification of DNA in vitro: The polymerase chain reaction. Cold Spring Harbor Symp. Quant. Biol. 51: 263-273.

2. Gyllensten, U.B. 1989. PCR and DNA sequencing. BioTechniques 7: 700-708.

3. Mullis, K. 1991. The polymerase chain reaction in an anemic mode: How to avoid cold oligodeoxyribonuclear fusion. PCR Methods Applic. 1: 1-5.

4. Saunders, N., W. Zollinger, and V.B. Rao. 1993. A rapid and sensitive strategy employed for amplification and sequencing of por A from a single colony forming unit of Neisseria meningitidis. Gene 137: 153-162.

5. Rao, V.B. 1994. Direct sequencing of polymerase chain reaction amplified DNA. Anal. Biochem. 216: 1-14.

6. Tabor, S. and C.C. Richardson. 1987. DNA sequence analysis with a modified bacteriophage T7 DNA polymerase. Proc. Natl. Acad. Sci. 84: 4767-4771.

7. Barr, P.J., R.M. Thayer, P. Laybourn, R.C. Najarian, F. Sela, and D.R. Tolan. 1986. 7-Deaza2 -deoxyguanosine-5'-triphosphate: Enhanced resolution in M13 dideoxy sequencing. BioTechniques 4: 428-432. 
8. Bachmann, B., W. Luke, and G. Hunsmann. 1990. Improvement of PCR amplified DNA sequencing with the aid of detergents. Nucleic Acids Res. 18: 1309.

9. Kusukawa, N., T. Uemori, K. Asada, and I. Kato. 1990. Rapid and reliable protocol for direct sequencing of material amplified by the polymerase chain reaction. BioTechniques 9: 66-71.

10. Gyllensten, U.B. and H.A. Erlich. 1988. Generation of single stranded DNA by the polymerase chain reaction and its application to direct sequencing of the HLA-DQ $\alpha$ locus. Proc. Natl. Acad. Sci. 85: 7652-7656.

11. Murray, V. 1989. Improved double-stranded DNA sequencing using the linear polymerase chain reaction. Nucleic Acids Res. 17: 8889.

12. Lee, J.-S. 1991. Alternative dideoxy sequencing of double-stranded DNA by cyclic reactions using Taq polymerase. DNA Cell Biol. 10: 67-73.

13. Rao, V.B. and N.B. Saunders. 1992. A rapid polymerase chain reaction-directed sequencing strategy using a thermostable DNA polymerase from Thermus flavus. Gene 113: 17-23.

14. Ruano, G. and K.K. Kidd. 1991. Coupled amplification and sequencing of genomic DNA. Proc. Natl. Acad. Sci. 88: 2815-2819.

15. Innis, M.A., K.B. Myambo, D.H. Gelfand, and M.A-D. Brow. 1988. DNA sequencing with Thermus aquaticus polymerase and direct sequencing of polymerase chain reaction-amplified DNA. Proc. Natl. Acad. Sci. 85: 9436-9440.

16. Tabor, S. and C.C. Richardson. 1989. Effect of manganese ions on the incorporation of dideoxynucleotides by bacteriophage T7 DNA polymerase and Escherichia coli DNA polymerase I. Proc. Natl. Acad. Sci. 86: 4076-4080.

17. Arnheim, N. and H. Erlich. 1992. Polymerase chain reaction strategy. Annu. Rev. Biochem. 61: 131-156

18. Fawcett, T.W. and S.G. Bartlett. 1990. An effective method for eliminating "artifact banding" when sequencing double-stranded DNA templates. BioTechniques 8: 46-48.

19. Fuller, C.W. 1989. Using T7 gene 6 exonuclease to prepare single stranded templates for sequencing. Edit. Comments 16: 1-8. 


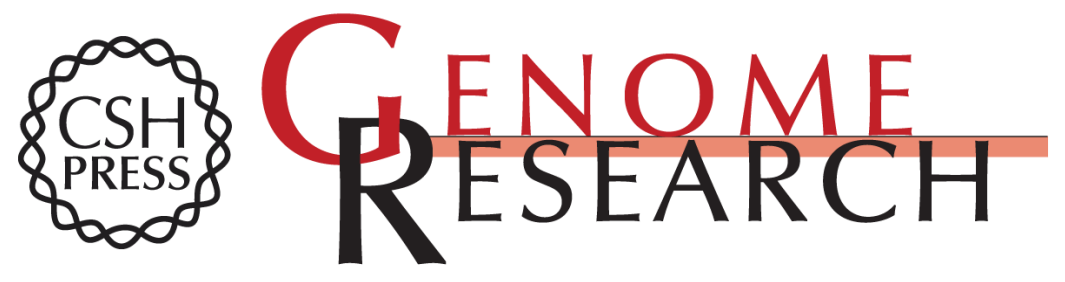

\section{Strategies for direct sequencing of PCR-amplified DNA.}

V B Rao

Genome Res. 1994 4: S15-S23

References This article cites 19 articles, 6 of which can be accessed free at: http://genome.cshlp.org/content/4/1/S15.full.html\#ref-list-1

\section{License}

Email Alerting Receive free email alerts when new articles cite this article - sign up in the box at the Service top right corner of the article or click here.

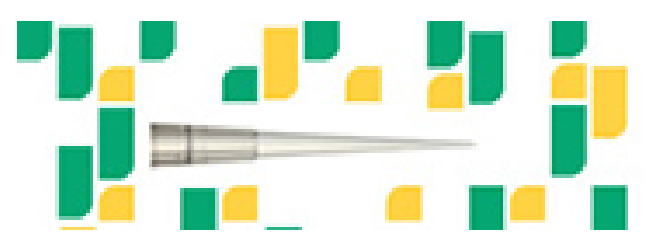

To subscribe to Genome Research go to: https://genome.cshlp.org/subscriptions 